Neurosurg Focus 18 (4):E6, 2005

\title{
The transsphenoidal approach
}

\author{
A historical perspective
}

\author{
Adam S. Kanter, M.D., Aaron S. Dumont, M.D., Ashok R. Asthagiri, M.D., \\ Rod J. Oskouian, M.D., John A. Jane JR., M.D., AND Edward R. LaWs JR., M.D. \\ Department of Neurological Surgery, University of Virginia Health System, Charlottesville, Virginia
}

\begin{abstract}
Over the last century, the transsphenoidal approach has evolved into the first-line method of treatment for sellar as well as select groups of parasellar and suprasellar lesions. The journey to its current popularity has been marked by controversy and near abandonment in the late 1920s, followed by its renaissance in the late 1960s. Despite the profound skepticism with which this procedure was viewed, several visionary neurosurgeons persevered through its nadir in popularity, preserving this surgical corridor to the skull base. Advances in medical and surgical techniques, paralleling an improved understanding of pituitary pathophysiology, contributed to its resurgence. The transsphenoidal procedures now performed stem from an array of modifications and refinements accumulated through nearly 100 years of medical and surgical evolution. This era's critical innovations and neurosurgical personalities are the topic of this historical overview.
\end{abstract}

\section{KEY WORDS - transsphenoidal surgery - pituitary surgery • history of neurosurgery • historical perspective}

The frontal transcranial approach to the sella turcica was first described by Fedor Krause ${ }^{45}$ of Berlin in 1905 after others had attempted and failed to perform surgical intervention for pituitary tumors. ${ }^{8}$ In 1906, Sir Victor Horsley of London reported a series of 10 operations in which he successfully reached the pituitary via transfrontal and subtemporal approaches. Pioneering neurosurgeons including Walter Dandy, ${ }^{13}$ George Heuer, ${ }^{25}$ Charles Frazier, ${ }^{18,19}$ and Harvey Cushing ${ }^{11,12}$ improved on this initial work, providing the foundation for contemporary transcranial approaches. The difficulties associated with these early transcranial operations, including high morbidity and mortality rates, provided an impetus for the development of extracranial approaches to sellar lesions.

According to Liu, et al.,${ }^{54}$ based on the initial work of Giordano, who proposed a transfacial approach to the pituitary gland in 1897 Hermann Schloffer of Austria reported the first successful resection of a pituitary tumor via a transsphenoidal approach in March of 1907. With local anesthesia provided by cocaine, Schloffer performed a three-stage procedure that appeared to represent a modification of contemporaneous approaches to treat sphenoid sinusitis. ${ }^{59,60}$ In the first stage, a nasal incision was extended to the glabella, the nose was reflected laterally to the right, and the nasal turbinates and septum were removed. The second stage entailed removal of the vomer and sphenoid rostrum with entry into the sphenoid sinus. In the final stage, the sphenoid mucosa was exenterated and the sellar floor was opened with a chisel. The symptoms improved postoperatively, but the patient ultimately died several months later due to the effects of obstructive hydrocephalus, with massive intraventricular tumor extension confirmed at autopsy.

Theodor Kocher modified the approach in 1909 by resecting the septum submucosally to expand visualization within the sella. ${ }^{43}$ Although sparing the frontal, ethmoidal, and maxillary sinuses, the septum was still approached through an overt midline incision on the bridge of the nose. Not until 1910, based on a route to the sphenoid sinus that his mentor, Hajek, used for surgical treatment of sinusitis did Oskar Hirsch of Vienna demonstrate the first completely endonasal transseptal transsphenoidal procedure. ${ }^{26,31,46}$ Hirsch performed a multiple-stage tumor resection over a 5-week period, with each session performed after application of local anesthesia. The patient's visual symptoms improved dramatically, following which Hirsch embarked on efforts to develop more effective and efficient surgical techniques, beginning with the addition of the nasal speculum.

Also in 1910, Albert Halstead of Chicago described the sublabial gingival approach to the sphenoid. ${ }^{22}$ Using this technique, he was able to preserve the cartilaginous septum with superior retraction, thus obtaining more pleasing postoperative aesthetic outcomes. Harvey Cushing further refined the transsphenoidal sublabial approach to the sella, until abruptly abandoning its use from 1929 to 1932 in favor of the transcranial approach. ${ }^{10-12}$ The reasons for Cushing's return to the transcranial approach are not entirely known, although it is thought that he considered the extent of resection and intraoperative complications to be more easily evaluated and dealt with from above. He also believed that without accurate means of preoperative 
tumor type determination, a transcranial approach, which was suitable for any lesion encountered, was more appropriate. His preferences were publicized when his 2000th tumor resection (an acidophilic adenoma) was performed via a transfrontal approach. As would be expected, the majority of the neurosurgical community followed Cushing's lead.

Despite its popular rejection, Hirsch continued to perform the endonasal transseptal transsphenoidal procedure. Traveling from Vienna to Boston, he acquired a reputation and moniker as an "obscure voice in the wilderness." 65
Hirsch was not a lone transsphenoidal enthusiast; Norman Dott, who studied Cushing's transsphenoidal approach at the Peter Bent Brigham Hospital from 1923 to 1924, continued to use and modify the approach after his return to the Royal Infirmary in Edinburgh. ${ }^{15} \mathrm{He}$ designed instruments specifically for the transsphenoidal route, such as a speculum with an attached lighting apparatus. ${ }^{47}$ Grace Allison, a professional photographer by trade, publicized Dott's success with the procedure after herself undergoing a successful resection of a pituitary lesion that had caused severe visual loss when she was a child.
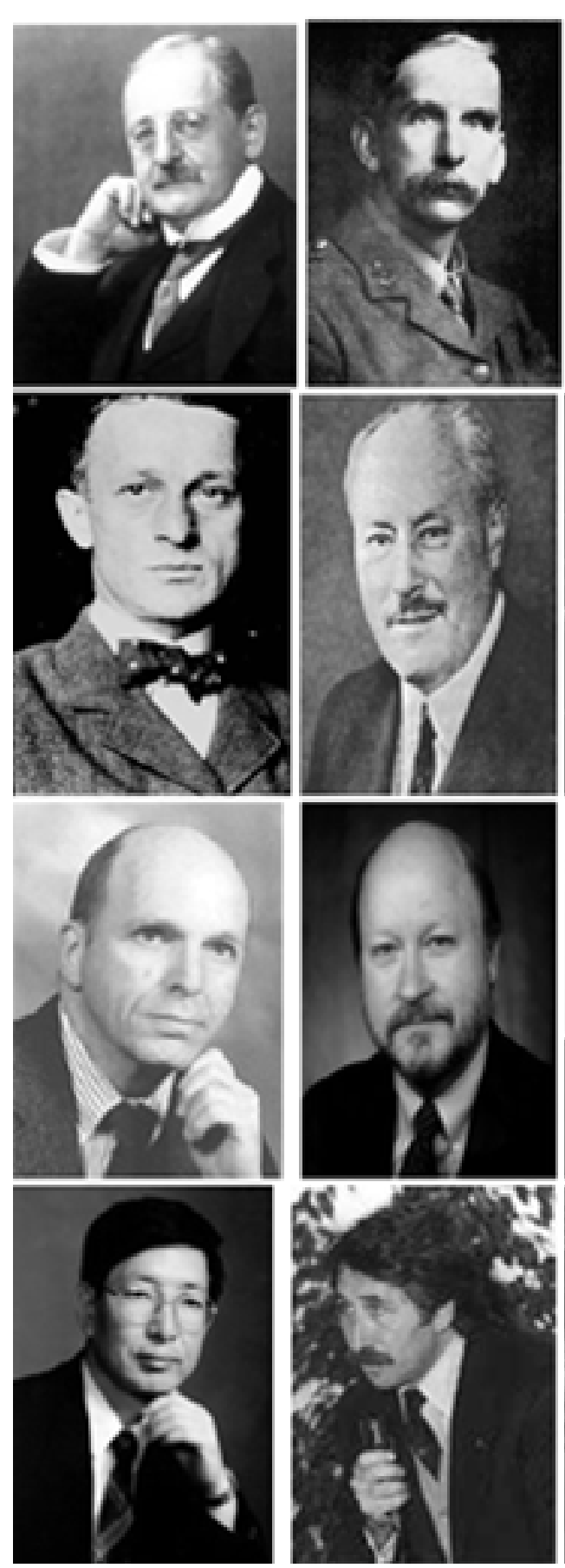
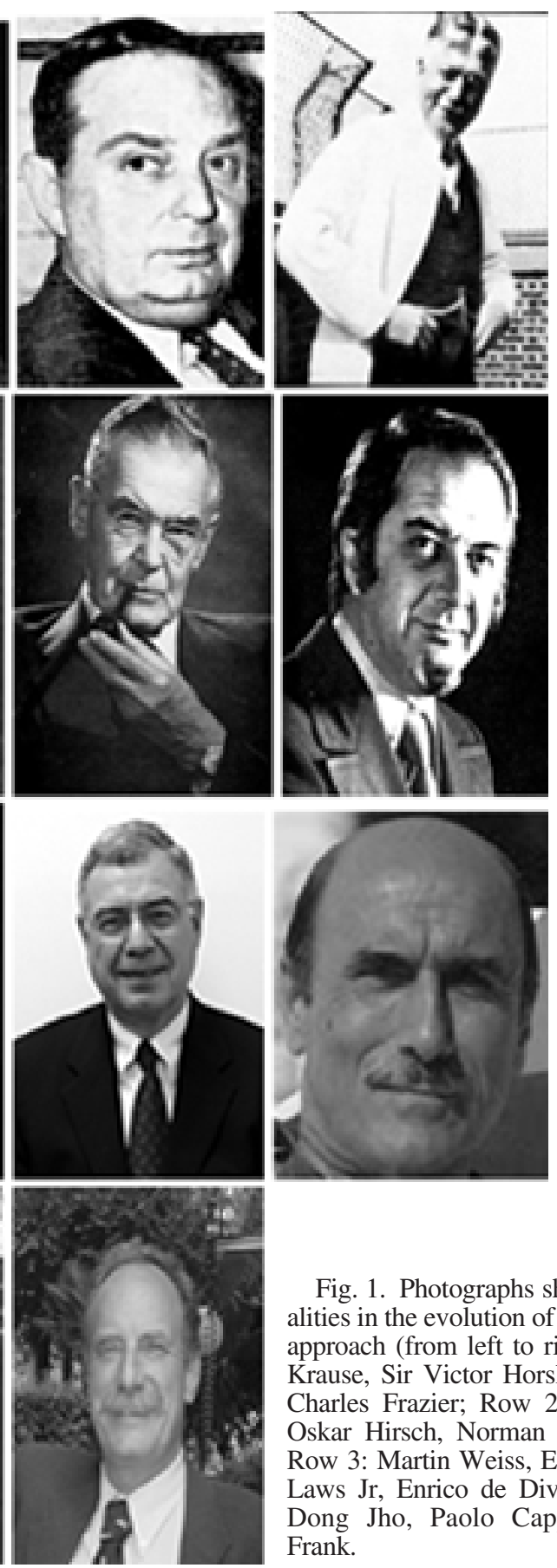

Fig. 1. Photographs showing key personalities in the evolution of the transsphenoidal approach (from left to right) Row 1: Fedor Krause, Sir Victor Horsley, Walter Dandy, Charles Frazier; Row 2: Harvey Cushing, Oskar Hirsch, Norman Dott, Jules Hardy; Row 3: Martin Weiss, Ed Oldfield, Edward Laws Jr, Enrico de Divitiis; Row 4: HaeDong Jho, Paolo Cappabianca, Giorgio Frank. 
Gerard Guiot, a French neurosurgeon, learned the technique from Dott in the 1950s and introduced intraoperative radiofluoroscopic guidance for trajectory confirmation. ${ }^{21}$ Jules Hardy from Montreal learned these techniques from Guiot and subsequently augmented them with the incorporation of the operating microscope, which provided dramatically superior illumination and magnification. ${ }^{23,24,62}$ Using microscopic dissection techniques, Hardy introduced the concept of microadenomectomy and demonstrated the possibility of surgical cure in patients with hyperfunctioning lesions not visualized on preoperative imaging. It was at this time that the surgical aim in pituitary surgery underwent a remarkable expansion, from its sole purpose of mass effect decompression to that of a sophisticated method for complex endocrinological symptom relief. Equally significant advances in the fields of endocrinology and radiology during this period indisputably contributed to the transsphenoidal renaissance that occurred in the late 1960s. Fluoroscopy was introduced, hormones were isolated, their physiological roles elucidated, and radioimmunoassays were developed for both diagnosis and posttreatment surveillance. ${ }^{39,52,53,56}$ These innovations provided the foundation for the modern transsphenoidal approach to simple intrasellar lesions that is used universally by neurosurgeons today.

Further refinements, including the introduction of the endoscope as the primary or adjunctive imaging modality, use of frameless stereotactic guidance, and aggressive resection of the cranial base have provided corridors to previously inaccessible tumors while preserving anatomical structures. ${ }^{1-4,7,9,14,16,17,28-30,32-38,40,41,55,58,61}$ Principles of cranial base surgery were extrapolated to transsphenoidal surgery by Martin Weiss at the University of Southern California, who published his experience with the "extended" approach in $1987 .{ }^{61}$ In this approach, Weiss described removal of the tuberculum sellae and posterior planum sphenoidale to achieve access to tumors with suprasellar, parasellar, and/or anterior cranial base extension. The approach also provided a passageway for the safe and effective resection of certain primary suprasellar tumors in the setting of a normalsized sella, while preserving the healthy pituitary gland. This approach has revolutionized the treatment of lesions such as craniopharyngiomas, tuberculum sellae meningiomas, and Rathke cleft cysts. As contemporary neurosurgical leaders, including Oldfield, Kato, Laws, Jho, Frank, de Divitiis, and Cappabianca further modify the procedure and expand the armamentarium of specialized instrumentation, the indications for this approach continue to grow. ${ }^{5-7,14,17,27,28,32,36-38,40,42,44,48-51}$

The transsphenoidal approach is the result of an evolutionary process rather than a revolutionary one (Fig. 1). It has involved the innovative thoughts and perseverance of multiple generations of neurosurgical pioneers, advances in medical science and surgical technique, and technological progress, all of which continue to develop today. ${ }^{46}$ The corridor continues to expand, with the superior limits of the approach extending well into the third ventricle and the inferior limits now including the craniocervical junction. ${ }^{20,57}$, 63,64 Brain retraction is minimized and the morbidity and mortality rates have become exceedingly low. Improving technical experience, advanced instrumentation, and fiberoptic technology will undeniably facilitate radical resection with better preservation of sellar and suprasellar structures.

\section{References}

1. Arai H, Sato K, Okuda, et al: Transcranial transsphenoidal approach for tuberculum sellae meningiomas. Acta Neurochir 142:751-757, 2000

2. Cappabianca P, Alfieri A, Thermes S, et al: Instruments for endoscopic endonasal transsphenoidal surgery. Neurosurgery 45: 392-396, 1999

3. Cappabianca P, Buonamassa S, Cavallo LM, et al: Neuroendoscopy: present and future applications. Clin Neurosurg 51: 186-190, 2004

4. Cappabianca P, Cavallo LM, Colao A, et al: Endoscopic endonasal transsphenoidal approach: outcome analysis of 100 consecutive procedures. Minim Invasive Neurosurg 45: 193-200, 2002

5. Cappabianca P, Cavallo LM, Colao A, et al: Surgical complications associated with the endoscopic endonasal transsphenoidal approach for pituitary adenomas. J Neurosurg 97:293-298, 2002

6. Cappabianca P, Cavallo LM, Esposito F, et al: Sellar repair in endoscopic endonasal transsphenoidal surgery: results of 170 cases. Neurosurgery 51:1365-1372, 2002

7. Cappabianca P, de Divitiis E: Endoscopy and transsphenoidal surgery. Neurosurgery 54:1043-1050, 2004

8. Caton R, Paul FT: Notes on a case of acromegaly treated by operation. Br Med J 2:1421-1423, 1893

9. Couldwell WT, Weiss MH, Rabb C, et al: Variations on the standard transsphenoidal approach to the sellar region, with emphasis on the extended approaches and parasellar approaches: surgical experience in 105 cases. Neurosurgery 55: 539-550, 2004

10. Cushing H: Partial hypophysectomy for acromegaly: with remarks on the function of the hypophysis. Ann Surg 50: 1002 1017, 1909

11. Cushing H: The Pituitary Body and Its Disorders, Clinical States Produced by Disorders of the Hypophysis Cerebri. Philadelphia: Lippincott, 1912, pp 296-305

12. Cushing H: The Weir Mitchell Lecture. Surgical experiences with pituitary adenoma. JAMA 63:1515-1525, 1914

13. Dandy WE: A new hypophysis operation. Bull Johns Hopkins Hosp 29:154-155, 1918

14. de Divitiis E, Cappabianca P, Cavallo LM: Endoscopic transsphenoidal approach: adaptability of the procedure to different sellar lesions. Neurosurgery 51:699-707, 2002

15. Dott NM, Bailey P: A consideration of the hypophyseal adenomata. Br J Surg 13:314-366, 1925

16. Elias WJ, Chadduck JB, Alden TD, et al: Frameless stereotaxy for transsphenoidal surgery. Neurosurgery 45:271-277, 1999

17. Frank G, Pasquini E, Mazzatenta D: Extended transsphenoidal approach. J Neurosurg 95:917-918, 2001

18. Frazier $\mathrm{CH}$ : An approach to the hypophysis through the anterior cranial fossa. Ann Surg 57:145-150, 1913

19. Frazier $\mathrm{CH}$ : Choice of method in operations upon the pituitary body. Surg Gynecol Obstet 29:9-16, 1919

20. Frempong-Boadu AK, Faunce WA, Fessler RG: Endoscopically assisted transoral-transpharyngeal approach to the craniovertebral junction. Neurosurgery 51 (Suppl 5):S60-S66, 2002

21. Guiot G, Thibault B: L'exptirpation des adenomes hypophysaires par voie trans-sphenoidale. Neurochiurgia 1:133-150, 1959

22. Halstead AE: Remarks on the operative treatment of tumors of the hypophysis. With the report of two cases operated on by an oronasal method. Trans Am Surg Assoc 28:73-93, 1910

23. Hardy J: [Exercision of pituitary adenomas by trans-sphenoidal approach.] Union Med Can 91:933-945, 1962 (Fre)

24. Hardy J: [Surgery of the pituitary gland, using the transsphenoidal approach. Comparative study of 2 technical methods.] Union Med Can 96:702-712, 1967 (Fre) 
25. Heuer GJ: The surgical approach and the treatment of tumors and other lesions about the optic chiasm. Surg Gynecol Obstet 53:489-518, 1931

26. Hirsch O: Endonasal method of removal of hypophyseal tumors. With a report of two successful cases. JAMA 55: $772-774,1910$

27. Honegger J, Fahlbusch R, Buchfelder M, et al: The role of transsphenoidal microsurgery in the management of sellar and parasellar meningioma. Surg Neurol 39:18-24, 1993

28. Jane JA Jr, Dumont AS, Vance ML, et al: The transsphenoidal transtuberculum sellae approach for suprasellar meningiomas. Semin Neurosurg 14:211-217, 2003

29. Jane JA Jr, Thapar K, Alden TD, et al: Fluoroscopic frameless stereotaxy for transsphenoidal surgery. Neurosurgery 48: 1302-1308, 2001

30. Jane JA Jr, Thapar K, Kaptain GJ, et al: Pituitary surgery: transsphenoidal approach. Neurosurgery 51:435-444, 2002

31. Jane JA Jr, Thapar K, Laws ER Jr: A history of pituitary surgery. Oper Techn Neurosurg 5:200-209, 2002

32. Jho HD, Alfieri A: Endoscopic endonasal pituitary surgery: evolution of surgical technique and equipment in 150 operations. Minim Invasive Neurosurg 44:1-12, 2001

33. Jho HD, Carrau RL: Endoscopic endonasal transsphenoidal surgery: experience with 50 patients. J Neurosurg 87:44-51, 1997

34. Jho HD, Carrau RL: Endoscopy assisted transsphenoidal surgery for pituitary adenoma. Technical note. Acta Neurochir 138: 1416-1425, 1996

35. Jho HD, Carrau RL, Ko Y, et al: Endoscopic pituitary surgery: an early experience. Surg Neurol 47:213-223, 1997

36. Jho HD, Ha HG: Endoscopic endonasal skull base surgery: Part 1-The midline anterior fossa skull base. Minim Invasive Neurosurg 47:1-8, 2004

37. Kaptain GJ, Vincent DA, Sheehan JP, et al: Transsphenoidal approaches for the extracapsular resection of midline suprasellar and anterior cranial base lesions. Neurosurgery 49:94-101, 2001

38. Kato T, Sawamura Y, Abe H, et al: Transsphenoidal-transtuberculum sellae approach for supradiaphragmatic tumors: technical note. Acta Neurochir 140:715-719, 1998

39. Kendall EC, Mason HL, Meyers CS, et al: A physiologic and chemical investigation of the suprarenal cortex. J Biol Chem 114:Ivii-lviii, 1936

40. Kim J, Choe I, Bak K, et al: Transsphenoidal supradiaphragmatic intradural approach: technical note. Minim Invasive Neurosurg 43:33-37, 2000

41. Kitano M, Taneda M: Extended transsphenoidal approach with submucosal posterior ethmoidectomy for parasellar tumors. Technical note. J Neurosurg 94:999-1004, 2001

42. Kitano M, Taneda M: Subdural patch graft technique for watertight closure of large dural defects in extended transsphenoidal surgery. Neurosurgery 54:653-661, 2004

43. Kocher T: Ein Fall von Hypophysis Tumor mit operativer Heilung. Dtsch Z Chir 100:13-37, 1909

44. Kouri JG, Chen MY, Watson JC, et al: Resection of suprasellar tumors by using a modified transsphenoidal approach. Report of four cases. J Neurosurg 92:1028-1035, 2000

45. Krause F: Hirnchirurgie (freilegung do hypophyse). Dtsch Klin 8:953-1024, 1905

46. Lanzino G, Laws ER Jr: Key personalities in the development and popularization of the transsphenoidal approach to pituitary tumors: an historical overview. Neurosurg Clin N Am 14: $1-10,2003$

47. Lanzino G, Laws ER Jr, Feiz-Erfan I, et al: Transsphenoidal approach to lesions of the sella turcica: historical overview. Barrow Q 18:4-8, 2002

48. Laurent JJ, Jane JA, Laws ER Jr: A case of midline suprasellar tumor removed by an extended transsphenoidal skull base technique, in Kobayashi S (ed): Neurosurgery of Complex Vascular Lesions and Tumors. New York: Thieme, 2005, pp 174-177

49. Laws ER Jr: Transsphenoidal removal of craniopharyngioma. Pediatr Neurosurg 21 (Suppl 1):57-63, 1994

50. Laws ER Jr, Kern EB: Complications of transsphenoidal surgery. Clin Neurosurg 23:401-416, 1976

51. Laws ER Jr, Weiss MH, White WL: Craniopharyngioma. Skull Base 13:55-58, 2003

52. Li CH, Dixon JS: Human pituitary growth hormone. 32. The primary structure of the hormone: revision. Arch Biochem Biophys 146:233-236, 1971

53. Li CH, Evans HM, Simpson ME: Isolation and properties of the anterior hypophyseal growth hormone. J Biol Chem 159: 353 366,1945

54. Liu JK, Das K, Weiss MH, et al: The history and evolution of transsphenoidal surgery. J Neurosurg 95:1083-1096, 2001

55. Mason RB, Nieman LK, Doppman JL, et al: Selective excision of adenomas originating in or extending into the pituitary stalk with preservation of pituitary function. J Neurosurg 87: 343-351, 1997

56. Pasteels JL: [Administration of hypothalamic extracts to the rat pituitary in vitro, with a view to controlling the secretion of prolactin.] C R Hebd Seances Acad Sci 254:2664-2666, 1962 (Fre)

57. Pollack IF, Welch W, Jacobs GB, et al: Frameless stereotactic guidance. An intraoperative adjunct in the transoral approach for ventral cervicomedullary junction decompression. Spine 20:216-220, 1995

58. Romano A, Zuccarello M, van Loveren HR, et al: Expanding the boundaries of the transsphenoidal approach: a microana tomic study. Clin Anat 14:1-9, 2001

59. Schloffer H: Erfolgreiche Operationen eines Hypophysentumors auf Nasalem Wege. Wien Klin Wochenschr 20: 621-624, 1907

60. Schloffer H: Zur Frage der Operationen an der Hypophyse. Bruns Beitr Klin Chir 50:767-817, 1906

61. Weiss MH: Transnasal transsphenoidal approach, in Apuzzo MLJ (ed): Surgery of the Third Ventricle. Baltimore: Williams \& Wilkins, 1987, pp 476-494

62. Welbourn RB: The evolution of transsphenoidal pituitary microsurgery. Surgery 100:1185-1190, 1986

63. Welch WC, Kassam A: Endoscopically assisted transoraltranspharyngeal approach to the craniovertebral junction. Neurosurgery 52:1511-1512, 2003

64. Welch WC, Subach BR, Pollack IF, et al: Frameless stereotactic guidance for surgery of the upper cervical spine. Neurosurgery 40:958-964, 1997

65. Zervas NT: Reflections on the surgery of the pituitary. Clin Neurosurg 27:124-132, 1980

Manuscript received February 17, 2005

Accepted in final form March 18, 2005.

Address reprint requests to: Adam S. Kanter, M.D., Department of Neurological Surgery, University of Virginia Health System, P.O. Box 800212, Charlottesville, Virginia 22908. email: ask9z @ virginia.edu. 